\title{
TINDAKAN HUKUM TERHADAP PELAKU TINDAK PIDANA KORUPSI BERDASARKAN UNDANG-UNDANG NOMOR 20 TAHUN 2001 TENTANG PERUBAHAN ATAS UNDANG-UNDANG NOMOR 31 TAHUN 1999 TENTANG PEMBERANTASAN TINDAK PIDANA KORUPSI
}

\author{
oleh: \\ Hotben Gultom \\ Meima
}

\begin{abstract}
ABSTRAK
Terdapat beberapa inti pembahasan hukum berkaitan dengan tugas dan fungsi anggota kepolisian di Negara Republik Indonesia dalam menyelesaikan permasalahan yang kompleks, sehingga kinerja para anggota kepolisian secara profesional itu sangat diperlukan. Penting bagi para anggota kepolisian untuk lebih mendalami terkait aturan hukum, konsep hukum dan doktrin hukum yang semakin berkembang dimana tujuannya adalah untuk menghindari kesalahan penerapan dan pelaksanaan dalam penegakan hukum. Adapun permasalahan hukum dalam legal memorandum ini adalah apakah terhadap Meta Susanti dan dr. Onni Habie, MARS yang diduga telah melakukan tindak pidana korupsi dapat diterapkan Pasal 55, Pasal 56, Pasal 64, dan Pasal 415 KUHP serta Pasal 2, Pasal 3, dan Pasal 8 Undang-Undang Nomor 20 Tahun 2001 Tentang Perubahan Atas Undang-Undang Nomor 31 Tahun 1999 Tentang Pemberantasan Tindak Pidana Korupsi ? serta bagaimanakah tindakan hukum yang dapat dilakukan oleh Pihak Kepolisian terhadap Meta Susanti dan dr. Onni Habie, MARS yang diduga telah melakukan tindak pidana korupsi ? Hasil penelitian menyimpulkan bahwa peristiwa tindak pidana korupsi dana klaim BPJS UPT RSUD Lembang tahun anggaran 2017 yang diduga dilakukan oleh Meta Susanti Dan dr. Onni Habie, MARS, telah cukup memenuhi rumusan delik dalam Pasal 2, Pasal 3, dan Pasal 8 Undang-Undang Nomor 20 Tahun 2001 Tentang Perubahan Atas Undang-Undang Nomor 31 Tahun 1999 Tentang Pemberantasan Tindak Pidana Korupsi serta Pasal 55, Pasal 56, Pasal 64 dan Pasal 415 KUHP. Tindakan yang dapat dilakukan oleh Kepolisian Negara Republik Indonesia Daerah Jawa Barat, terhadap pelaku tindak pidana korupsi yaitu Meta Susanti Dan dr. Onni Habie, MARS, yaitu melakukan penyelidikan, penyidikan, penangkapan, pemeriksaan dan penahanan, serta menyerahkan berkas perkara ke Kejaksaan untuk dilakukan penuntutan.
\end{abstract}

Kata Kunci: Tindak Pidana Korupsi, Kepolisian, Penegakan Hukum

\section{PENDAHULUAN}

\section{Latar Belakang}

Meta Susanti merupakan Staf Rekam Medik UPT RSUD Lembang Kabupaten Bandung Barat dan saat ini Meta Susanti mempunyai jabatan sebagai pembantu bendahara penerimaan di UPT RSUD Lembang Kabupaten Bandung, yang berdasarkan Surat Keputusan Kepala Dinas Kesehatan Kabupaten Bandung Barat Nomor : 440/262.1/Dinkes tanggal 2 Januari 2015 dan berdasarkan Surat Tugas dari Kepala UPT RSUD Lembang Nomor 800/152/RSUDLembang/2015 tanggal 5 Maret 2015.

Meta Susanti dilahirkan di Bandung pada tanggal 14 April 1981 dari seorang ibu yang bernama Mimih Sukaemih (almarhumah) dan seorang ayah yang bernama Muntolib, dari kecil Meta Susanti tinggal dan dibesarkan di Jalan Sukajadi Kelurahan Pasteur Kecamatan Sukajadi Kota Bandung. Pada tahun 2003, Meta Susanti lulus dari D3 Kejuruan Rekam Medik Universitas Esa Unggul Jakarta, kemudian setelah lulus Meta Susanti bekerja sebagai tenaga honorer di Rumah Sakit Dustira Cimahi. Pada tahun 2005 Meta Susanti menikah dengan Rudianto dan diberi karunia 3 orang anak. 
Tahun 2011 Meta Susanti lulus tes CPNS, dan mulai bekerja sebagai Pegawai Negeri Sipil di Dinas Kesehatan Kabupaten Bandung Barat, kemudian pada tahun 2014 Meta Susanti menjabat sebagai Bendahara Penerimaan Pembantu pada UPT RSUD Lembang dan pada tahun 2018 Meta Susanti juga diberi amanah untuk menjabat sebagai Koordinator Rekam Medik pada UPT RSUD Lembang Kabupaten Bandung Barat.

Tugas pokok dan fungsi Meta Susanti sebagai Bendahara Penerimaan Pembantu di UPT RSUD Lembang Kabupaten Bandung Barat adalah menerima pendapatan rumah sakit baik yang dari kasir langsung ataupun dari pihak lain dalam hal ini BPJS Kesehatan, tugas lain yaitu menyetorkan pendapatan rumah sakit atau dana retribusi ke keuangan dinas namun sejak tahun 2017 penyetoran harus langsung ke kas daerah, dan juga Meta Susanti sebagai Bendahara Penerimaan Pembantu di UPT RSUD Lembang mempunyai tugas membuat laporan buku kas umum. Meta Susanti dalam menjalankan tugasnya mempunyai tanggung jawab langsung kepada Direktur UPT RSUD Lembang Kabupaten Bandung Barat, baik secara lisan maupun secara tulisan.

Meta Susanti merupakan pihak yang berperan penting dalam hal menerima pendapatan rumah sakit dalam hal ini BPJS Kesehatan. Perjanjian Kerjasama antara UPT RSUD Lembang dengan BPJS Kantor Cabang Cimahi ditandatangani oleh dr. Onnie Habie sebagai kepala UPT RSUD Lembang dan dr. Yudha Indraja sebagai sebagai Kepala BPJS Cabang Cimahi, karena dalam Perjanjian Kerjasama antara UPT RSUD Lembang dengan BPJS Kantor Cabang Cimahi menyepakati bahwa pembayaran klaimakan dilakukan melalui trasnfer maka dari itu pihak UPT RSUD Lembang diwajibkan membuka rekening yang harus disampaikan ke BPJS Cabang Cimahi dan dalam pembukaan rekening Kepala UPT RSUD Lembang mengajak Meta Susanti sebagai bendahara untuk membuka rekening atas nama UPT RSUD Lembang, dan dalam rekening yang berhak menandatangani adalah Kepala UPT RSUD Lembang yaitu dr. Onni Habie, MARS dan Bendahara UPT RSUD Lembang yaitu Meta Susanti.

Mekanisme pencairan dana klaim BPJS sesuai dengan surat kesepakatan atau surat perjanjian kerjasama antara BPJS Kesehatan Cabang Cimahi dengan UPT RSUD Lembang untuk tahun 2017 dan 2018 bahwa setiap pencairan klaim BPJS yang diajukan oleh UPT RSUD Lembang dan disetujui maka realisasasinya akan di transfer oleh pihak BPJS ke pihak rumah sakit melalui bank yang telah disepakati dan bank yang disepakati untuk tahun 2017 Bank Mandiri Cabang Lembang dan tahun 2018 adalah Bank Mandiri Cabang Setiabudi.

Dana klaim BPJS yang diterima UPT RSUD Lembang dan telah di transfer ke rekening UPT RSUD lembang adalah sebagai berikut :

1. Tahun 2017 masuk ke rekening Bank Mandiri Nomor 132-00-2443444-2 Cabang Lembang atas nama rekening UPT RSUD Lembang adalah sebagai berikut :

a. Tanggal 14 Pebruari 2017 sebesar Rp. 165.408.000,- (seratus enam puluh lima juta empat ratus delapan ribu rupiah).

b. Tanggal 16 Maret 2017 sebesar Rp. 374.737.600,- (tiga ratus tujuh puluh empat juta tujuh ratus tiga puluh tujuh ribu enam ratus rupiah).

C. Tanggal 18 April 2017 sebesar Rp. 316.860.600,- (tiga ratus enam betas juta delapan ratus enam puluh ribu enam ratus rupiah).

d. Tanggal 16 Mei 2017 sebesar Rp. 810.631.500,- (delapan ratus sepuiuh juta enam ratus tiga puluh satu ribu lima ratus rupiah).

e. Tanggal 15 Juni 2017 sebesar Rp. 435.017.200,- (empat ratus tiga puluh lima juta tujuh belas ribu dua ratus rupiah).

f. Tanggal 24 Juli 2017 sebesar Rp. 633.743.000,- (enam ratus tiga puluh tiga juta tujuh ratus empat puluh tiga ribu rupiah).

g. Tanggal 14 Agustus 2017 sebesar Rp. 385.984.500,- (tiga ratus delapan puluh lima juta sembilan ratus delapan puluh empat ribu lima ratus rupiah). Tanggal 15 
September 2017 sebesar Rp. 641.298.700,- (enam ratus empat puluh satu juta dua ratus sembilan puluh delapan ribu tujuh ratus rupiah).

h. Tanggal 26 September 2017 sebesar Rp. 157.024.300,- (seratus lima puluh tujuh juta dua puluh empat ribu tiga ratus rupiah).

i. Tanggal 13 Nopember 2017 sebesar Rp.510.519.300,- (lima ratus sepuiuh juta lima ratus sembilan belas ribu tiga ratus rupiah).

j. Tanggal 30 Nopember 2017 sebesar Rp.448.293.100,- (empat ratus empat puluh delapan juta dua ratus sembilan puluh tiga ribu seratus rupiah).

k. Tanggal 15 Desember 2017 sebesar Rp.642.529.700,- (enam ratus empat puluh dua juta lima ratus dua puluh sembilan ribu tujuh ratus rupiah).

Total dana masuk dari Januari sampai dengan Desember 2017 adalah Rp. 5.522.047.500,(lima milyar lima ratus dua puluh dua juta empat puluh tujuh ribu lima ratus rupiah).

2. Tahun 2018 masuk ke rekening Bank Mandiri Nomor 1320021103875 Cabang Setiabudi atas nama rekening UPT RSUD Lembang adalah sebagai berikut :

a. Tanggal 6 Februari 2018 sebesar Rp. 684.018.600,- (enam ratus delapan puluh empat juta delapan belas ribu enam ratus rupiah).

b. Tanggal 20 Februari 2018 sebesar Rp. 625.060.000,- (enam ratus dua puluh lima juta enam puluh ribu rupiah).

C. Tanggal 07 maret 2018 Sebesar Rp. 30.067.500,-, (tiga puluh juta enam puluh tujuh ribu lima ratus rupiah).

d. Tanggal 8 Maret 2018 sebesar Rp. 810.439.900,- (delapan ratus sepuiuh sembilan juta empat ratus tiga puluh sembilan ribu sembilan ratus rupiah).

e. Tanggal 13 April 2018 sebesar Rp. 682.642.600,- (enam ratus delapan puluh dua juta lima ratus empat puluh dua ribu enam ratus rupah).

f. Tanggal 16 Mei 2018 sebesar Rp. 883.491.500,- (delapan ratus delapan puluh tiga juta empat ratus sembilan puluh satu ribu lima ratus rupiah).

g. Tanggal 5 juni 2018 sebesar Rp. 7.822.855,- (tujuh juta delapan ratus dua puluh dua ribu delapan ratus lima puluh lima rupiah).

h. Tanggal 26 Juni 2018 sebesar Rp. 893.792.800,- (delapan ratus sembilan puluh tiga juta tujuh ratus sembilan puluh dua ribu delapan ratus rupiah).

i. Tanggal 19 Juli 2018 sebesar Rp. 761.651.700,- (tujuh ratus enam puluh satu juta enam ratus lima puluh satu ribu tujuh ratus rupah).

j. Tanggal 02 Agustus 2018 sebesar Rp. 8.154.349,- (delapan juta seratus lima

k. puluh empat ribu tiga ratus empat puluh sembilan rupiah).

I. Tanggal 6 September 2018 sebesar Rp. 1.714.938,- (satu juta tujuh ratus empat betas ribu sembilan ratus tiga puluh delapan rupiah).

m. Tanggal 12 September 2018 sebesar Rp.496.694.600,- (empat ratus sembilan puluh enam juta enam ratus sembilan puluh empat ribu enam ratus rupiah).

Total uang yang masuk ke rekening Bank Mandiri Cabang Setiabudi atas nama UPT RSUD Lembang dengan nomor Rekening 1320021103875 adalah Rp. 5.885.451.342,(lima milyar delapan ratus delapan puluh lima juta empat ratus lima puluh satu ribu tiga ratus empat puluh dua rupiah).

Sehingga total penerimaan dana klaim BPJS yang telah diterima RSUD Lembang untuk tahun 2017 dan 2018 adalah Rp 11.407.488.842,-- (sebelas milyar empat ratus tujuh juta empat ratus delapan puluh delapan ribu delapan ratus empat puluh dua rupiah). 
Penarikan dana klaim BPJS dari Bank Mandiri pada awalnya dilakukan oleh Meta Susanti selaku Bendahara Penerimaan dengan kepala UPT RSUD Lembang yaitu dr. Onni Habie, MARS. Penarikan dana klaim BPJS dilakukan dengan cara mendatangi Bank Mandiri dan melakukan penarikan dengan mengisi dan menanda tangani slip/formulir penarikan. Untuk penarikan dana klaim BPJS selanjutnya, terkadang Meta Susanti sendiri yang melakukan penarikan dana klaim BPJS, yang dilakukan dengan cara dr. Onni Habie, MARS menandatangani slip/formulir penarikan terlebih dahulu yang sudah dimintakan dari bank sebelumnya jika sudah ditandatangani dr. Onni Habie, MARS maka Meta Susanti datang dan melakukan penerikan sendiri ke bank.

Dana klaim BPJS yang sudah ditarik oleh Meta Susanti kemudian langsung disetorkan ke kas daerah, namun ada juga yang digunakan oleh Meta Susanti dan dr. Onni Habie, MARS, dan juga ada yang disimpan di loker keuangan di ruangan Meta Susanti atau ruang keuangan dr. Onni Habie, MARS sebagai UPT RSUD Lembang dan dana yang disimpan dalam loker tersebut disetorkan ke kas daerah untuk setoran berikutnya, namun ada juga dana yang digunakan oleh dr. Onni Habie, MARS dan Meta Susanti untuk kepentingan pribadi.

Dana klaim BPJS yang diterima UPT RSUD Lembang dan telah disetor ke kas daerah adalah :

1. Tahun 2017 dengan rincian sebagai berikut :

a. Tanggal 30 Mei 2017 disetorkan oleh Meta Susanti sejumlah Rp 553.898.300,- (lima ratus lima puluh tiga juta delapan ratus sembilan puluh delapan ribu tiga ratus rupiah). Dengan bukti setoran adalah Surat Tanda setoran nomor 01/STS/RSUD Lembang dan 02/STS/RSUD Lembang.

b. Tanggal 10 Juli 2017 disetorkan oleh Meta Susanti sejumlah Rp. 316.100 .600 (tiga ratus enam belas juta seratus ribu enam ratus rupiah). Dengan bukti setoran adalah Surat Tanda setoran nomor 03/STS/RSUD Lembang.

C. Tanggal 22 September 2017 disetorkan oleh Meta Susanti sejumlah Rp 348.567.900,(tiga ratus empat puuh delapan juta lima ratus enam puluh tujuh ribu sembilan ratus rupiah). Dengan bukti setoran adalah Surat Tanda setoran nomor 04/STS/RSUD Lembang.

d. Tanggal 17 Nopember 2017 disetorkan oleh Meta Susanti sejumlah Rp 462.093.600,(empat ratus enam puluh dua juta sembilan puluh tiga ribu enam ratus rupiah). Dengan bukti setoran adalah Surat Tanda setoran nomor 05/STS/RSUD Lembang.

e. Tanggal 7 Desember 2017 disetorkan oleh Meta Susanti sejumlah Rp 100.427.400,(seratus juta empat ratus dua puluh tujuh ribu empat ratus rupiah). Dengan bukti setoran adalah Surat Tanda setoran nomor 06/STS/RSUD Lembang.

f. Tanggal 28 Desember 2017 disetorkan oleh Meta Susanti sejumlah Rp 437.935.900,(empat ratus tiga puluh tujuh juta sembilan ratus tiga puluh lima ribu sembilan ratus rupiah). Dengan bukti setoran adalah Surat Tanda setoran nomor 07/STS/RSUD Lembang.

Total setoran ke Kas Daerah Kabupaten Bandung Barat untuk tahun 2017 sebesar Rp 2.219.023.700,- (dua milyar dua ratus sembilan betas juta dua puluh tiga ribu tujuh ratus rupiah).

2. Tahun 2018 dengan rincian sebagai berikut :

a. Tanggal 23 Pebruari 2018 disetorkan oleh Meta Suanti sejumlah Rp 385.989.500,(tiga ratus delapan puluh lima juta sembilan ratus delapan puluh sembilan ribu lima ratus rupiah). Dengan bukti setoran adalah Surat Tanda setoran nomor 01/STS/RSUD Lembang. 
b. Tanggal 22 Mei 2018 disetorkan oleh Meta Suanti sejumlah Rp 630.067.500,- (enam ratus tiga puluh juta enm puluh tujuh ribu lima ratus rupiah). Dengan bukti setoran adalah Surat Tanda setoran nomor 02/STS/RSUD Lembang.

C. Tanggal 15 Agsutsu 2018 disetorkan oleh Meta Suanti sejumlah Rp 476.930.500,-(empat ratus tujuh puluh enam juta sembilan ratus tiga piluh ribu lima ratus rupiah). Dengan bukti setoran adalah Surat Tanda setoran nomor 03/STS/RSUD Lembang.

Total setoran ke Kas Daerah Kabupaten Bandung Barat untuk tahun 2017 sebesar Rp 1.492.987.500,- (satu milyar empat ratus sembilan puluh dua juta sembilan ratus delapan puluh tujuh ribu lima ratus rupiah).

Total setoran dana klaim BPJS yang disetorkan oleh Meta Susanti ke kas daerah Kabupaten Bandung Barat untuk tahun 2017 dan 2018 hanyalah sebesar Rp 3.712.011.200,(tiga milyar tujuh ratus dua belas juta sebelas ribu dua ratus rupiah). Dana yang tidak disetorkan oleh Meta Susanti dari tahun 2017 dan 2018 seluruhnya sejumlah Rp 7.715.323.900,- (tujuh milyar tujuh ratus lima belas juta tiga ratus dua puluh tiga ribu sembilan ratus rupiah). Dana yang tidak disetorkan oleh Meta Susanti tersebut digunakan untuk kepentingan pribadi Meta Susanti dan dr. Onni Habei, MARS.

Dana klaim BPJS yang tidak disetorkan oleh Meta Susanti pada awalnya tergoda untuk meminjam dana yang disimpan di loker keuangan Meta Susanti, dana tersebut dipinjam oleh Meta Susanti dan dr. Onni Habie, MARS. Setelah lama meminjam, dana klaim BPJS yang seharusnya disetorkan ke kas daerah Kabupaten Bandung Barat tersebut bukannya dikembalikan, namun digunakan secara sengaja oleh Meta Susanti dan dr. Onni Habie, MARS, dana tersebut digunakan untuk kepentingan pribadi Meta Susanti dan dr. Onni Habie, MARS.

Meta Susanti telah menggunakan untuk kepentingan prbadi dana klaim BPJS tahun 2017 dan tahun 2018 sebesar Rp. 3.036.410.570,- (tiga milyar tiga puluh enam juta empat ratus sepuluh ribu lima ratus tujuh puluh rupiah), sedangkan dr. Onni Habie, MARS telah menggunakan untuk kepentingan pribadi dana klaim BPJS sebesar Rp. 2.154.624.030,- (dua milyar seratus lima puluh empat juta enam ratus dua puluh empat ribu tiga puluh rupiah), namun ada selisih sebesar Rp. 2.524.289.300,- (dua milyar lima ratus dua puluh empat juta dua ratus delapan puluh sembilan ribu tiga ratus rupiah) dari total dana klaim BPJS yang tidak disetorkan oleh Meta Susanti sebesar Rp. Rp 7.715.323.900,- (tujuh milyar tujuh ratus lima belas juta tiga ratus dua puluh tiga ribu sembilan ratus rupiah), hal tersebut terjadi karena untuk setiap penarikan uang klaim BPJS jika tidak setorkan ke kas daerah maka disimpan oleh Meta Susanti di loker ruangan Meta Susanti, hingga dana klaim BPJS digunakan oleh Meta Susanti dan dr. Onni Habie, MARS yang dalam pengambilan dana klaim BPJS sudah pasti melalui Meta Susanti karena kunci loker yang pegang hanya Meta Susanti sendiri dan dari selisih uang yang sebesar Rp. 2.524.289.300,- (dua milyar lima ratus dua puluh empat juta dua ratus delapan puluh sembilan riibu tiga ratus rupiah) digunakan oleh Meta Susanti dan sebagian besar oleh dr. Onni Habie, MARS yang sudah meminjam uang sejak awal tahun 2017, namun untuk penggunaan oleh dr. Onni Habie, MARS buktinya tidak ada karena tidak dicatat oleh Meta Susanti.

\section{Identifikasi Masalah}

1. Apakah terhadap Meta Susanti dan dr. Onni Habie, MARS yang diduga telah melakukan tindak pidana korupsi dapat diterapkan Pasal 55, Pasal 56, Pasal 64, dan Pasal 415 KUHP serta Pasal 2, Pasal 3, dan Pasal 8 Undang-Undang Nomor 20 Tahun 2001 Tentang Perubahan Atas Undang-Undang Nomor 31 Tahun 1999 Tentang Pemberantasan Tindak Pidana Korupsi ? 
2. Bagaimanakah tindakan hukum yang dapat dilakukan oleh Pihak Kepolisian terhadap Meta Susanti dan dr. Onni Habie, MARS yang diduga telah melakukan tindak pidana korupsi ?

\section{TINJAUAN PUSTAKA}

Menurut Mochtar Kusumaatmadja bahwa "Hukum adalah keseluruhan kaidah serta semua asas yang mengatur pergaulan hidup dalam masyarakat dan bertujuan untuk memelihara ketertiban serta meliputi berbagai lembaga dan proses guna mewujudkan berlakunya kaidah sebagai suatu kenyataan dalam masyarakat". ${ }^{1)}$

Karakteristik hukum adalah memaksa disertai dengan ancaman dan sanksi. Tetapi hukum bukan dipaksa untuk membenarkan persoalan yang salah, atau memaksa mereka yang tidak berkedudukan dan tidak beruang. Agar peraturan-peraturan hidup kemasyarakatan benar-benar dipatuhi dan ditaati sehingga menjadi kaidah hukum, maka peraturan kemasyarakatan tersebut harus dilengkapi dengan unsur memaksa. Dengan demikian, hukum mempunyai sifat mengatur dan memaksa setiap orang supaya mentaati tata tertib dalam masyarakat serta memberikan sanksi yang tegas (berupa hukuman) terhadap siapa saja yang tidak mau mematuhinya. ${ }^{2}$

Para pakar hukum pidana mengungkapkan bahwa tujuan hukum pidana adalah untuk menakut-nakuti seseorang agar tidak melakukan kejahatan (preventif). Kedua, untuk mendidik atau memperbaiki orang-orang yang sudah menandakan dirinya suka melakukan kejahatan agar menjadi orang yang baik tabi'atnya (represif). ${ }^{3)}$

Moeljatno memberikan pengertian :

"Perbuatan pidana adalah perbuatan yang dilarang oleh suatu aturan hukum, larangan mana disertai ancaman (sanksi) yang berupa pidana tertentu, bagi barangsiapa yang melanggar larangan tersebut, dapat juga dikatakan bahwa perbuatan pidana adalah perbuatan yang oleh suatu aturan hukum dilarang dan diancam pidana asal saja dalam pada itu diingat bahwa larangan ditujukan pada perbuatan (yaitu suatu keadaan atau kejadian yang ditimbulkan oleh kelakuan orang), sedangkan ancaman pidananya ditujukan kepada orang yang menimbulkan kejadian itu." ${ }^{4}$

Larangan dan ancaman pidana memiliki hubungan yang erat dikarenakan antara kejadian dan pihak yang menimbulkan kejadian tersebut memiliki hubungan yang erat pula, tidak dapat dipisahkan antara yang satu dengan yang lainnya, sehingga untuk menyatakan hubungan yang erat tersebut maka digunakan perkataan perbuatan, yaitu suatu penjelasan abstrak yang merujuk kepada dua keadaan konkrit. Pertama adanya kejadian yang tertentu dan kedua adanya orang yang berbuat yang menimbulkan kejadian itu, sedangkan mengenai strafbaar feit, Moeljatno menyatakan bahwa :5)

1. Feit dalam strafbaar feit berarti handeling, kelakuan atau tingkah laku;

2. Pengertian strafbbar feit dihubungkan dengan kesalahan orang yang mengadakan kelakuan tadi.

1)1) Mochtar Kusumaatmadja, Hukum, Masyarakat, dan Pembangunan, Binacipta, Bandung, 2005, hlm.62

2)2) Suharto dan Junaidi Efendi, Panduan Praktis Bila Menghadapi Perkara Pidana, Mulai Proses Penyelidikan Sampai Persidangan, Prestasi Pustaka, Jakarta, 2010, hlm.25

hlm. 20

3)3) Wirjono Prodjodikoro, Asas-Asas Hukum Pidana di Indonesia, PT. Refika Aditama, Bandung, 2003,

4)4) Moeljatno, Asas-Asas Hukum pidana, Rineka Cipta, Jakarta, 1993, hlm. 54.

5)5) Ibid 
Mengenai unsur-unsur tindak pidana Moeljatno menyatakan bahwa unsur atau elemen perbuatan tindak pidana adalah :6)

a. Kelakuan dan akibat (perbuatan)

b. Hal-ikhwal atau keadaan yang menyertai perbuatan

c. Keadaan tambahan yang memberatkan pidana

d. Unsur melawan hukum yang obyektif

e. Unsur melawan hukum yang subyektif

Atang Ranoemihardja memberikan klasifikasi jenis-jenis tindak pidana (delik) dalam hukum pidana menjadi kejahatan (misdrijven) tindak pidana (delik) yang tercantum dalam KUHP Buku II Pasal 104 sampai dengan Pasal 448, dan pelanggaran (overtredingen) tindak pidana (delik) yang tercantum dalam KUHP Buku III Pasal 449 sampai dengan Pasal 569.7)

Saat ini korupsi telah memasuki tahap yang tidak terbatas, dalam melakukan praktik korupsi, para birokrat tidak lagi sekedar ingin memenuhi kebutuhannya, tetapi cenderung menjadi serakah. Jalan semakin terbuka lebar untuk menuju kearah itu para birokrat telah menemukan mekanisme yang sangat efektif untuk dengan cepat mengumpulkan harta sebanyak-banyaknya melalui praktik korupsi." ${ }^{\prime \prime)}$

Fockema Andreae memberikan deskripsi bahwa, "kata korupsi berasal dari bahasa latin corruption atau corroptus, Eropa seperti Inggris corruption, corrupt, Perancis corruption, Belanda corruptive dan Indonesia korupsi yang secara harafiah adalah kebusukan, keburukan, kebejatan, ketidakjujuran, dapat disuap, tidak bermoral, penyimpangan dari kesucian". ${ }^{9}$ Sedangkan istilah korupsi oleh Poerwadarminta "korupsi ialah perbuatan yang buruk seperti penggelapan uang, penerimaan uang sogok dan sebagainya". ${ }^{10)}$

Turut serta atau deelneming diatur dalam Pasal 55 dan Pasal 56 KUHP, yang berbunyi sebagai berikut :

Pasal 55 KUHP berbunyi :

(1)Dipidana sebagai pembuat (dader) sesuatu perbuatan pidana :

1. Mereka yang melakukan, yang menyuruh melakukan dan yang turut serta melakukan perbuatan;

2. Mereka yang dengan memberi atau menjanjikan sesuatu, dengan menyalahgunakan kekuasaan atau martabat, dengan kekerasan, ancaman atau penyesatan, atau dengan memberi kesempatan, sarana atau keterangan, sengaja menganjurkan orang lain supaya melakukan perbuatan.

(2)Terhadap penganjur, hanya perbuatan yang sengaja dianjurkan sajalah yang diperhitungkan, beserta akibat-akibatnya.

Pasal 56 berbunyi:

Dipidana sebagai pembantu (medeplichtige) sesuatu kejahatan :

1. Mereka yang sengaja memberi bantuan pada waktu kejahatan dilakukan;

2. Mereka yang sengaja memberi kesempatan, sarana atau keterangan untuk melakukan kejahatan.

${ }^{6) 6)}$ Moeljatno., Op.Cit., hlm. 58.

7)7) Atang Ranoemihardja., Op.Cit., hlm. 83.

${ }^{8) 8)}$ Darli Darwis, Birokrasi di Indonesia Sangat Rawan KKN, Aditya Media, Yogyakarta, 1999, hlm. 57.

9)9) Fockema Andreae., dalam Andi Hamzah, Pemberantasan Korupsi Melalui Hukum Pidana Nasional dan Internasional, Raja Grafindo Persada, Jakarta, 2005, hlm. 5.

10)10) Poerwadarminta., dalam Andi Hamzah., Ibid 


\section{PEMBAHASAN}

Peristiwa tindak pidana korupsi dana klaim BPJS UPT RSUD Lembang tahun anggaran 2017 yang diduga dilakukan oleh Meta Susanti Dan dr. Onni Habie, MARS, menurut hemat penulis telah cukup memenuhi rumusan delik dalam Pasal 2, Pasal 3, dan Pasal 8 Undang-Undang Nomor 20 Tahun 2001 Tentang Perubahan Atas Undang-Undang Nomor 31 Tahun 1999 Tentang Pemberantasan Tindak Pidana Korupsi serta Pasal 55, Pasal 56, Pasal 64 dan Pasal 415 KUHP.

Unsur-unsur dalam Pasal 55 dan Pasal 56 KUHP pun menurut hemat penulis telah terpenuhi dalam hal menjerat Meta Susanti dan dr Onni Habie, MARS, karena Meta Susanti selain turut serta menyelewengkan dana klaim BPJS tahun anggaran 2017 dan tahun anggaran 2018 sebesar Rp. 3.036.410.570,- (tiga milyar tiga puluh enam juta empat ratus sepuluh ribu lima ratus tujuh puluh rupiah), Meta Susanti pun memberikan pertolongan kepada dr. Onni Habie, MARS, dengan cara memberikan uang dana klaim BPJS yang tidak disetorkan ke kas daerah, uang yang digunakan oleh dr. Onni Habie, MARS hasil dari penyelewengan dana klaim BPJS sebesar sebesar Rp. 2.154.624.030,- (dua milyar seratus lima puluh empat juta enam ratus dua puluh empat ribu tiga puluh rupiah). Dan juga terdapat selisih uang yang sebesar Rp. 2.524.289.300,- (dua milyar lima ratus dua puluh empat juta dua ratus delapan puluh sembilan riibu tiga ratus rupiah) digunakan oleh Meta Susanti dan sebagian besar oleh dr. Onni Habie, MARS yang sudah meminjam uang sejak awal tahun 2017, namun untuk penggunaan oleh dr. Onni Habie, MARS buktinya tidak ada karena tidak dicatat oleh Meta Susanti.

Meta Susanti dalam melakukan penyelewengan dana klaim BPJS untuk tahun anggaran 2017 dan tahun anggaran 2018 tidak hanya melakukan satu kali perbuatan, namun berulang kali sehingga mencapai angka Rp. 3.036.410.570,- (tiga milyar tiga puluh enam juta empat ratus sepuluh ribu lima ratus tujuh puluh rupiah), oleh sebab itu rumusan delik dalam Pasal 64 KUHP telah terpenuhi.

Tindakan hukum yang dapat dilakukan oleh Kepolisian Negara Republik Indonesia Daerah Jawa Barat, terhadap pelaku tindak pidana korupsi yaitu Meta Susanti Dan dr. Onni Habie, MARS, terlebih dahulu melakukan penyelidikan terhadap kasus tersebut, sesuai dengan Pasal 1 butir 5 KUHAP. Setelah dilakukan penyelidikan, kemudian dapat ditingkatkan menjadi upaya penyidikan berdasarkan Pasal 1 butir 2 KUHAP.

Proses selanjutnya setelah dilakukan penyidikan, adalah melakukan penangkapan terhadap pelaku yaitu Meta Susanti Dan dr. Onni Habie, MARS yang diduga melakukan tindak pidana korupsi. Cara pelaksanaan penangkapan seperti yang diatur dalam Pasal 18 KUHAP.

Setelah melakukan penangkapan terhadap pelaku yang diduga melakukan tindak pidana korupsi tersebut, maka langkah selanjutnya terhadap pelaku yang diduga melakukan tindak pidana korupsi tersebut yaitu Meta Susanti Dan dr. Onni Habie, MARS adalah dilakukan pemeriksaan. Pada waktu melakukan proses pemeriksaan, maka terhadap tersangka pelaku tindak pidana korupsi yaitu Meta Susanti Dan dr. Onni Habie, MARS, dapat dilakukan penahanan.

Setelah semua langkah-langkah ditempuh sesuai dengan proses acara pidana, maka langkah selanjutnya yang dapat dilakukan oleh Kepolisian Negara Daerah Jawa Barat, adalah menyerahkan berkas perkara kepada Kejaksaan, untuk dilakukan penuntutan terhadap pihak yang melakukan tindak pidana korupsi tersebut oleh Jaksa Penuntut Umum.

\section{KESIMPULAN DAN SARAN}

Peristiwa tindak pidana korupsi dana klaim BPJS UPT RSUD Lembang tahun anggaran 2017 yang diduga dilakukan oleh Meta Susanti Dan dr. Onni Habie, MARS, telah cukup memenuhi rumusan delik dalam Pasal 2, Pasal 3, dan Pasal 8 Undang-Undang Nomor 
20 Tahun 2001 Tentang Perubahan Atas Undang-Undang Nomor 31 Tahun 1999 Tentang Pemberantasan Tindak Pidana Korupsi serta Pasal 55, Pasal 56, Pasal 64 dan Pasal 415 KUHP. Tindakan hukum yang dapat dilakukan oleh Kepolisian Negara Republik Indonesia Daerah Jawa Barat, terhadap pihak yang melakukan tindak pidana korupsi yaitu Meta Susanti Dan dr. Onni Habie, MARS, dengan melakukan penyelidikan, penyidikan, penangkapan, pemeriksaan dan penahanan.

Pengetahuan institusi pihak Kepolisian mengenai ilmu hukum perlu untuk dipertajam lagi, hal ini diperlukan untuk menjaga wibawa hukum agar tidak tercoreng dari tindakan sewenang-wenangan oleh anggota Kepolisian yang secara sembarangan menerapkan pasalpasal yang tidak relevan terhadap suatu tindak pidana. Peningkatan terhadap sumber daya manusia dalam Institusi Kepolisian harus lebih diterapkan dikarenakan dengan semakin berkembangnya aturan-aturan baru, adanya perubahan aturan, beragamnya dan meningkatnya modus operandi kejahatan, maka hal tersebut harus segera diterapkan agar penegakan hukum dapat berjalan sebagaimana mestinya.

\section{DAFTAR PUSTAKA}

\section{A. Buku}

Andi Hamzah, Pemberantasan Korupsi Melalui Hukum Pidana Nasional dan Internasional, Raja Grafindo Persada, Jakarta, 2005.

Darli Darwis, Birokrasi di Indonesia Sangat Rawan KKN, Aditya Media, Yogyakarta, 1999.

Mochtar Kusumaatmadja, Hukum, Masyarakat, dan Pembangunan, Binacipta, Bandung, 2005. Moeljatno, Asas-Asas Hukum pidana, Rineka Cipta, Jakarta, 1993

Suharto dan Junaidi Efendi, Panduan Praktis Bila Menghadapi Perkara Pidana, Mulai Proses Penyelidikan Sampai Persidangan, Prestasi Pustaka, Jakarta, 2010.

Wirjono Prodjodikoro, Asas-Asas Hukum Pidana di Indonesia, PT. Refika Aditama, Bandung, 2003.

\section{B.Perundang-Undangan}

Kitab Perundang-Undangan Hukum Pidana

Undang-Undang Nomor 20 Tahun 2001 Tentang Perubahan Atas Undang-Undang Nomor 31

Tahun 1999 Tentang Pemberantasan Tindak Pidana Korupsi 